\title{
A De Novo Tool to Measure the Preclinical Learning Climate of Medical Faculties in Turkey
}

Nilufer Demiral Yilmaz ${ }^{a}$

Ege University

Serpil Velipasaoglu ${ }^{b}$

Dokuz Eylül University

Hatice Sahin ${ }^{c}$

Ege University

Bilge Uzun Basusta ${ }^{d}$

Hacettepe University

Ozlem Midik ${ }^{\mathrm{e}}$

Ondokuz Mayis University
Ozlem Coskun ${ }^{\dagger}$

Gazi University

Isıl Irem Budakoglug

Gazi University

Sumer Mamakli

Akdeniz University

Funda Ifakat Tengiz

Izmir University of Economics

Halil Ibrahim Durak

Ege University

Sema Ozan ${ }^{k}$

Dokuz Eylül University

\begin{abstract}
Although several scales are used to measure general and clinical learning climates, there are no scales that assess the preclinical learning climate. Therefore, the purpose of this study was to develop an effective measurement tool in order to assess the preclinical learning climate. In this cross-sectional study, data were collected from 3,540 preclinical medical students of six medical faculties in Turkey. The methodology included the following activities: generate an item pool, receive expert opinions, perform a pretest to purify the instrument, and conduct factor and reliability analyses. According to the factor analysis, eight factors were determined and their contribution to the variance was $50.39 \%$. In addition, the item factor loadings ranged from 31 to .91 , Cronbach's alpha coefficients for the subscales ranged from .72 to .77, and the item-total correlation coefficients for the subscales ranged from .44 to .76 . All the items significantly discriminated between the lowand high-performing students $(t=99.57 ; p=.01)$. The scale included 52 items with the following subscales: management, teaching, teaching staff, institutional commitment, emotions, inter-student relationships, physical environment, and motivation. The analysis of this newly developed Preclinical Learning Climate Scale (PLCS) indicated that its psychometric properties are appropriate and this scale can be employed to evaluate medical education programs.
\end{abstract}

Keywords: Education $\bullet$ Medical $\bullet$ Undergraduate $\bullet$ Learning climate $\bullet$ Psychometrics 
Learning climates are important as they directly influence the learners' work within them (and vice versa) and provide a measure to determine the effectiveness of such climates in educational institutions (Dornan, Mann, Scherpbier, Spencer, \& Norman, 2011). This topic has been one of the main subjects of focus in previous evaluations of medical education programs (Kennedy, Lilley, Kiss, Littvays, \& Harden, 2013; Soemantri, Herrera, \& Riquelme, 2010; WFME Standards, 2003). Learning climate has been defined as the quality of the learning environment as perceived by teaching staff and students (Genn, 2001). When students attend a new educational institution, they not only become acquainted with the curriculum but also become aware of the learning climate when they take exams, attend classes, or participate in activities (Dornan et al., 2011; Roff \& McAleer, 2001). In this regard, the curriculum's structure and its management, the educational-social activities offered to the students, and the school's relationship with the environment all shape the school's learning climate (Demiral Yilmaz, 2010; Roff \& McAleer, 2001). Thus, by measuring the learning climate, an educational program can be evaluated to identify its positive and negative aspects (based on the opinions of teaching staff and students), following which interinstitutional comparisons can be performed and overall improvements can be achieved (Dornan et al., 2011).

An examination of recent medical educational environment instruments reveals that there are many differences between educational institutions. These differences are in part attributable to the fact

a Corresponding author

Nilufer Demiral Yilmaz (PhD), Department of Medical Education, Faculty of Medicine, Ege University, Bornova, Izmir 35100 Turkey

Research areas: Medical education; Education administration; Vocational skills training; Assessment and evaluation; Psychometrics

Email: nilufer.demiraldgmail.com

b Asst. Prof. Serpil Velipasaoglu (MD, PhD), Department of Medical Education, Faculty of Medicine, Dokuz Eylül University, İnciralti, Izmir 35340 Turkey

Email: serpil.velipasaogluagmail.com

c Assoc. Prof. Hatice Sahin (MD, PhD), Department of Medical Education, Faculty of Medicine, Ege University, Bornova, Izmir 35100 Turkey

Email: hatice.sahin8dgmail.com

d Bilge Uzun Basusta (PhD), Department of Medical Education and Informatics, Faculty of Medicine, Hacettepe University, Sihhiye, Ankara 06100 Turkey

Email: n.bilgeuzundagmail.com

e Ozlem Midik (MD, PhD), Department of Medical Education, Faculty of Medicine, Ondokuz Mayis University, Atakum, Samsun 55280 Turkey Email: dromidik@gmail.com

f Ozlem Coskun (MD, PhD), Department of Medical Education, Faculty of Medicine, Gazi University, Yenimahalle, Ankara 06560 Turkey

Email: drocoskundgmail.com

g Prof. Ișil Irem Budakoglu (MD, PhD), Department of Medical Education, Faculty of Medicine, Gazi University, Yenimahalle, Ankara 06560 Turkey

Email: isilirembdgmail.com

h Sumer Mamakli (MD, PhD), Department of Medical Education, Faculty of Medicine, Akdeniz University, Kampus, Antalya 07070 Turkey

Email: smamaklidakdeniz.edu.tr

i Funda Ifakat Tengiz (MD, PhD), Vocational School of Health Services, Izmir University of Economics, Balçova, Izmir 35330 Turkey

Email: funda.tengizQizmirekonomi.edu.tr

j Prof. Halil Ibrahim Durak (MD, PhD), Department of Medical Education, Faculty of Medicine, Ege University, Bornova, Izmir 35100 Turkey

Email: durakhidgmail.com

k Assoc. Prof. Sema Ozan (MD, PhD), Department of Medical Education, Faculty of Medicine, Dokuz Eylül University, Inciralti, Izmir 35340 Turkey

Email: semaozandagmail.com 
that the instruments were often tailored to a specific setting of interest (Schönrock-Adema, BouwkampTimmer, van Hell, \& Cohen-Schotanus, 2012). As shown in Figure 1, recent scales have accessed the overall learning climate, the individual clinical phase, or certain themes that can influence the learning climate. The scales that have accessed the overall learning climate include the Medical Student Education Environment Measure (MSLES) (Marshall, 1978); the scale developed by Polali and Price (2000); the Medical Education Environment Measure (MEEM) (Roff, McAleer, Harden, \& AlQahtani, 1996); and the Dundee Ready Education Environment Measure (DREEM) (Roff, 2005; Roff et al., 1996; Roff et al., 1997). The MSLES was the first measurement tool used to evaluate the learning climate among medical students. The DREEM, another widely used scale to assess undergraduate medical education, distinguishes the learning environment in traditional medical schools from the learning environment in innovative medical schools and measures both clinical and preclinical phases in a program (Dornan et al., 2011; Soamentri et al., 2010). This tool was previously employed in a study on medical students in Turkey (Demirören, Palaoglu, Kemahli, Özyurda, \& Ayhan, 2008). Furthermore, some scales are specific to clinical education such as the Clinical Learning Climate
Scale (CLCS) (Demiral Yilmaz, 2010; Wangsaturak \& McAleer, 2008), the Manchester Clinical Placement Index (MCPI) (Dornan et al., 2011), and the Undergraduate Clinical Education Environment Measure (UCEEM) (Strand et al., 2013). However, no scales specifically measure the preclinical learning climate in undergraduate medical education.

It is impossible to conduct clinical studies without performing preclinical studies in undergraduate medical education. The basic difference between the two learning climates is the transition from the preclinical phase to the clinical phase. Although the main objectives in the preclinical phase are to foster learning through small or large group activities and provide assessments of the students' competency, the overall objective in the clinical phase is to learn by participating in daily practices (Dornan et al., 2011; Riley, 2009).

To date, in order to ensure vertical and horizontal integration, medical training programs have undergone several changes. More specifically, the preclinical period currently includes learning activities such as early clinical contact, simulation practice, and skills labs, while the clinical period consists of basic medical science courses in addition to the clinical applications (Cate, 2007; Harden \& Davis, 1995; McClean, 2004). Despite

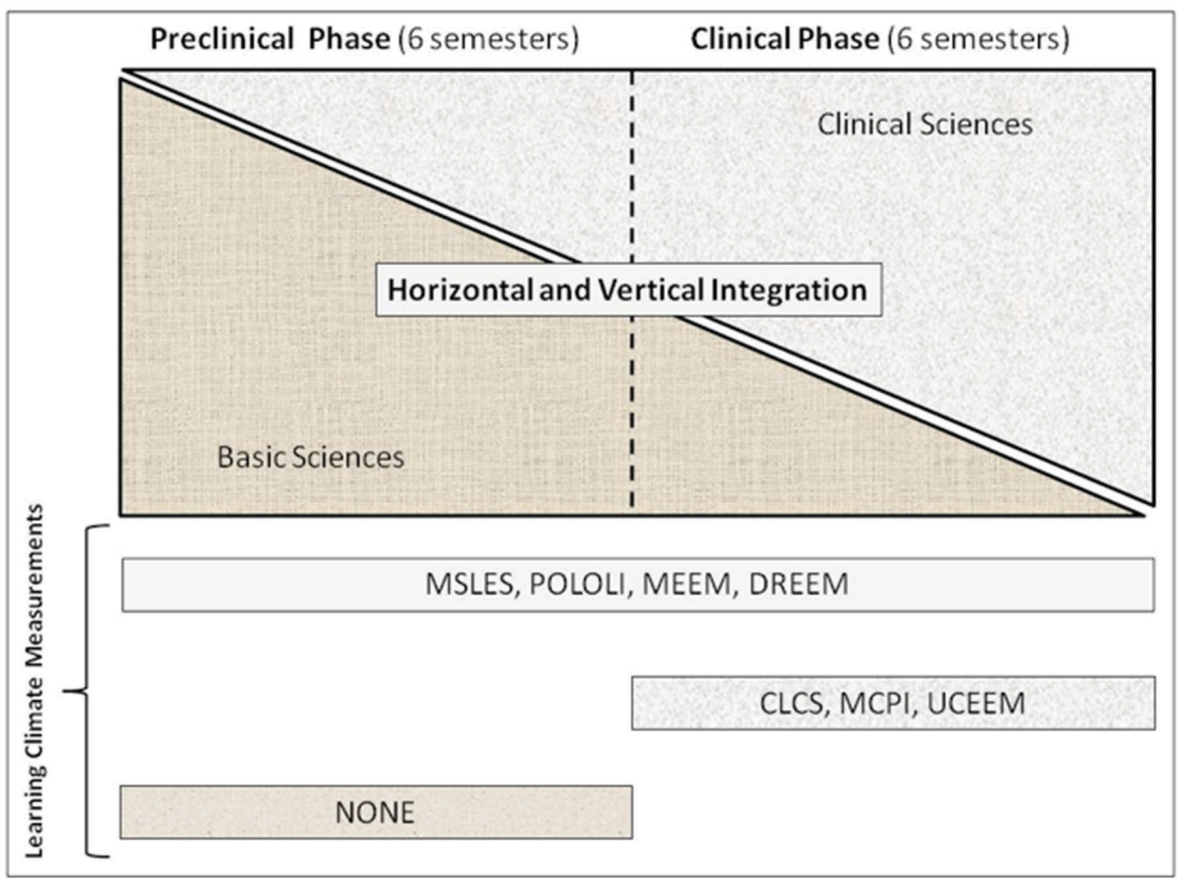

Figure 1: Scales used to assess the learning climate in medical education programs. 
these efforts, the preclinical period continues to bear its distinctive features. These differences between the two phases can change the learning climate and affect the students. During the clinical stage, which is known to be a major source of stress for students (Dahlin \& Runeson, 2007; Sandars, Patel, Steele, \& Mcareavey, 2014), the students become more involved as future members of the profession. However, this is not the case for the preclinical phase. Although it has been shown that it is important to assess the learning environments of each phase of undergraduate medical education (Soemantri et al., 2010; Wangsaturak \& McAleer, 2008), the purpose of the present study was to develop a measurement tool to specifically assess the learning climate of the preclinical stage.

\section{Methods}

This cross-sectional study focused on six wellestablished medical faculties in four different geographical regions of Turkey. In Turkey, medical education generally lasts for six years (12 semesters), with the first three years as the preclinical phase and the second three years as the clinical phase. During the preclinical phase, medical students acquire basic medical knowledge and skills in simulated environments in order to prepare themselves for the clinical phase. Teaching is primarily through classroom lectures and practical applications in small groups. During the clinical phase, students develop their medical knowledge and skills through clinical rotations based on their preclinical learning. These education programs are structured in such a way as to allow the horizontal and vertical integration of both phases. Among the six medical faculties participating in this study, two implemented a problem-based learning (PBL) program, whereas the other four implemented a system-based integrated program. During the development of the scale, there was no predetermined sample size. Thus, all of the preclinical students $(N=5,833)$ in the aforementioned six medical faculties were included in this study.

\section{Development of the Instrument}

This Preclinical Learning Climate Scale (PLCS) was developed in five stages. While the validity analysis (content, construct) was carried out in the first four stages, the reliability analysis was conducted in the fifth stage.
Literature Review and Generation of the Item Pool: In Stage 1, a literature review was performed by the research team. In addition, the feedback collected from the participating students in the preclinical phase was taken into account. The students' feedback focused on various aspects such as their opinions regarding their educators, theoretical and practical educational activities, educational resources, learning motivation, information, and social facilities. Based on the literature review and the feedback data, a conceptual framework related to the learning climate (teaching, learning experience, educational resources, success, human relations, educators, assistant educators, emotions, health and stress, motivation, and management) was determined and the item pool was generated. Consensus regarding the items to be included in the initial version of the instrument was established using the Delphi panel technique. For this approach, the list of items was electronically sent to the researchers of this study by the principal researcher. The researchers were then requested to assess the appropriateness of the items with a standard form in accordance with certain criteria (i.e., whether the items represent the property to be measured, whether the items can be understood by the target population, whether the statements are clear enough, and whether the items are relevant to the conceptual framework). This technique was repeated three times until a consensus on the items was reached. As a result, the initial version of the instrument was developed.

Expert Review Panel: In Stage 2, in order to determine the content validity of the initial version of the instrument, 10 outside experts (nine postgraduates in medical education and one psychologist) from different medical education departments were consulted. After the initial version of the instrument was developed, the expert panel evaluated the scale to determine whether it was consistent with the purpose of the study. The experts were then requested to evaluate each item of the initial version of the instrument as "appropriate" or "not appropriate" in accordance with the criteria used in the Delphi panel. They were also asked to provide any suggestions for the items that they considered "not appropriate." Based on the experts' opinions, the content validity ratio (CVR) for each of the items in the scale was calculated using Lawshe's technique (Lawshe, 1975). In this technique, if the number of experts is 10 , then the CVR is expected to be a minimum of .62 at the $\alpha=.05$ level of significance (Veneziano \& Hooper, 1997). Thus, the preliminary instrument was developed with a calculated CVR score that was over 62 . 
Instructions describing the purpose of the scale and the how the items are marked were provided with the preliminary instrument. The preliminary instrument utilized a five-point Likert scale ranging from 1 (strongly disagree) to 5 (strongly agree). An assessment expert examined the style of the preliminary instrument while a Turkish linguist evaluated the clarity of the language. In Stages 1 and 2 , the content validity of the preliminary instrument was also examined.

Pretest and Purification of the Instrument: In Stage 3, the preliminary instrument was given to a group of student volunteers $(n=20)$ who evaluated the items in terms of meaningfulness, readability, comprehensibleness, sentence length, and clarity of meaning. At a subsequent meeting, two researchers obtained the students' views (both orally and in writing) following which their opinions were evaluated by the research team. After the pretest, the preliminary instrument was deemed ready for implementation.

Data: The preliminary instrument was given to the preclinical students in the medical faculties between April 2012 and May 2012. Prior to the application of the scale, the students were informed about the purpose of the study and the confidentiality of their personal data, following which their consents were obtained. The collected data were entered into a standard database by the researcher(s) in the relevant faculty. After data quality control was performed, any surveys with missing values were removed. The final data were gathered and analyzed.

Factor Analysis: In Stage 4, the construct validity of the preliminary instrument was examined with exploratory factor analysis (EFA). The KaiserMeyer-Olkin (KMO) and Bartlett's test of sphericity was conducted to determine whether the factor analysis was applicable (Sharma, 1996). During the EFA, the number of subscales in the scale was determined via the principal components analysis and the Promax rotation method. Based on the rule that the sample size of an item with a factor loading of .30 should be at least 350 (Hair, Tatham, Anderson, \& Black, 1998), the cut-off point for the factor loading values was accepted as .30.

At the conclusion of Stage 4, the definitive instrument was developed by testing the construct validity of the scale. Discriminant validity analysis was conducted to support the construct validity of the data collected with the definitive instrument. During this assessment, the mean scores obtained by the students from the instrument were compared in terms of the following variables: curriculum, their year in the faculty, whether they failed a class and repeated it, whether it was their own decision to attend the medical faculty, their academic grade point averages, and their perceptions of success.

Reliability Analysis: In Stage 5, the reliability analysis of the definitive instrument was performed. In order to determine the reliability of the instrument, Cronbach's alpha coefficient was calculated. The cut-off point for Cronbach's alpha coefficient was accepted as .70 (Nunnaly, 1978). To investigate the relationship between each item and the total score of the scale, the item-total correlations were calculated. In addition, to assess the discrimination of each item on the scale, the top and bottom $27 \%$ of the groups that received the highest and lowest scores, respectively, were compared.

To evaluate the validity evidence in this study, five headings published by The American Psychological, Education Research Associations and National Council on Measurement in Education were used (AERA-APA-NCMA, 1999). First, content validity evidence was obtained from the data generated through the literature review, preclinical students' feedback, item pool, Delphi panel, and expert review panel. Validity evidence based on the response process was obtained from the data generated from the sample method, response rate, self-reported method, informed consent, anonymous response, five-point Likert scale, data quality control, and standard database. Validity evidence based on the internal structure was obtained from the data generated through EFA, Cronbach's alpha, itemtotal correlation, and item discrimination. Validity evidence based on the relation to other variables was obtained from the data on observed and expected scores, and discriminant analysis. Finally, to obtain evidence based on consequences, the reports recorded in each stage of the research were shared and evaluated by the researchers.

At the end of the five stages, the validity and reliability of the scale were established, the subscales were identified, and the min-max scores for the scale and subscales were determined. There was no cut-off point for the scores obtained from the scale. Scores that were closer to the maximum score indicated that the learning climate was positively perceived. Moreover, the statistical analysis was performed using PASW Statistics software for Windows (SPSS, Inc., IBM) Version 18.0. 


\section{Ethical Considerations}

This study was approved by the Ethics Committee of the Ege University Faculty of Medicine (Decision Number: 11-6.1/10,) and all the students' written and verbal consents were obtained. There were no conflicts of interest in this study.

\section{Results}

\section{Characteristics of the Study Group}

Among the 5,833 preclinical students attending the six medical faculties in this study, $61 \%(n=3,540)$ responded to the preliminary instrument. The mean age of the students in the study group was $20 \pm 1.45$ years $(\min =17-\max =36)$. Among the students, $54 \%$ were male, $38 \%$ were first-year students, $32 \%$ were second-year students, $29 \%$ were third-year students, $6 \%$ failed a class and repeated it, and $85 \%$ willingly chose the medical school. Regarding their academic grade point averages, $7 \%$ of the students had less than $59,86 \%$ had between 60 and 84 , and $7 \%$ had 85 and higher. Finally, $17 \%$ of the students considered themselves "not successful," while 52\% stated that they were "moderately successful" and $31 \%$ felt that they were "successful." Figure 2 presents the algorithm related to the development process of the PLCS, which lasted for two years (June 2011-June 2013).

\section{Initial Version of the Instrument}

Upon completion of the literature review, a 235 item pool was generated. The researchers reached a consensus on 85 items (at the end of the third round of the Delphi panel), and the initial version of the instrument was based on this material.

\section{Preliminary Instrument}

In order to examine the content validity of the initial version of the instrument, 10 outside experts were consulted, and the content validity ratio (CVR) was calculated for each of the items in the scale. It was found that the CVR for 64 of the 85 items in the initial version of the instrument was above .62. The other 21 items were excluded on the basis of the experts' opinions. The preliminary instrument only included the items whose CVR was over .62. An assessment expert examined the preliminary instrument, and according to the Turkish linguist, it required no revisions and it was ready for pretesting. The content validity of the preliminary instrument was established after the Delphi and expert panels. In total, 20 medical student volunteers participated in the pretesting phase of the preliminary instrument (64 items). The students stated that the items in the scale were meaningful, readable, and understandable. They

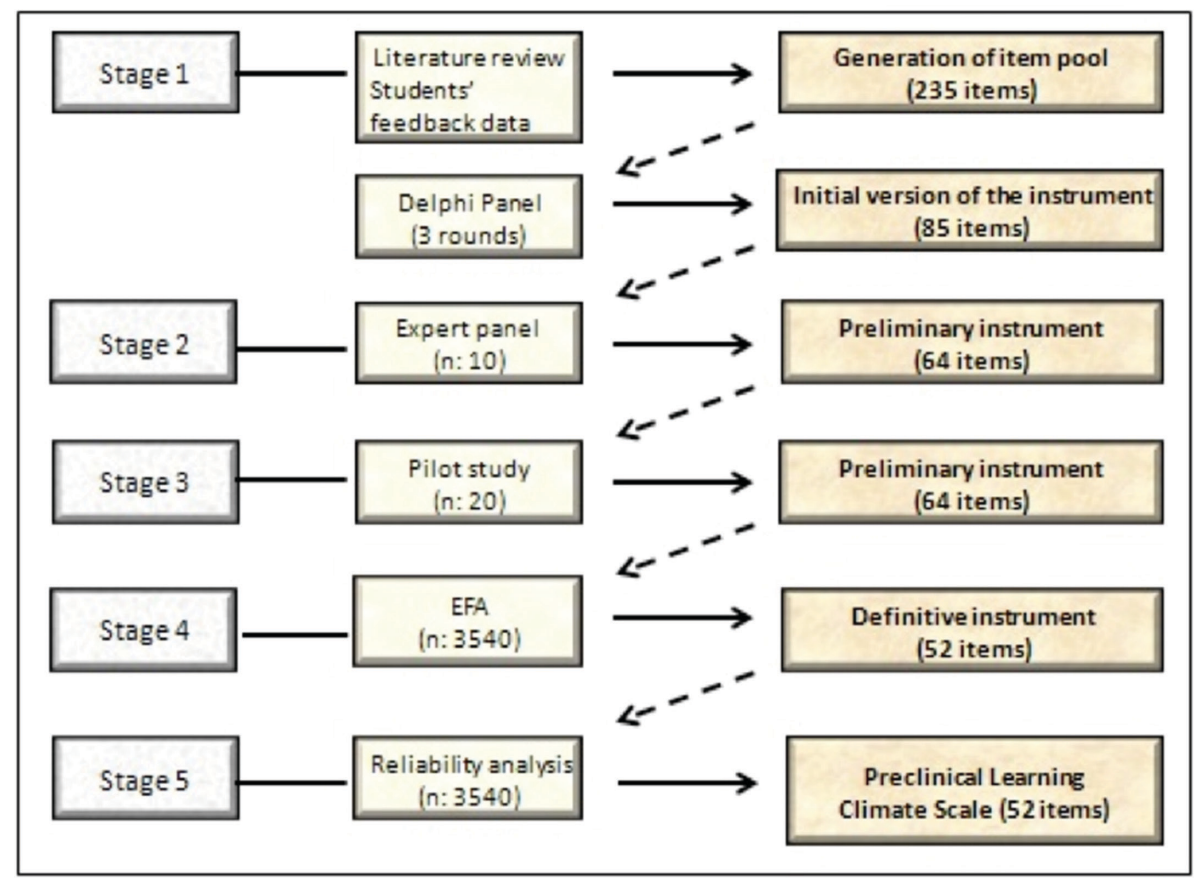

Figure 2: Development process of the PLCS. 
Table 1

Factor Structure of the Preliminary Instrument

\begin{tabular}{cccccc}
\hline Factors & Communalities & Eigenvalues & $\begin{array}{c}\text { Percentage of Total } \\
\text { Variance Explained }\end{array}$ & $\begin{array}{c}\text { Cumulative Percentage of } \\
\text { Total Variance Explained }\end{array}$ & $\begin{array}{c}\text { Factor Loadings } \\
\text { F1 }\end{array}$ \\
\hline F2 & $0.42-0.60$ & 12.78 & 24.58 & 24.58 & $0.77-0.38$ \\
F3 & $0.40-0.62$ & 2.92 & 5.62 & 30.20 & $0.79-0.38$ \\
F4 & $0.38-0.68$ & 2.56 & 4.93 & 35.13 & $0.79-0.41$ \\
F5 & $0.38-0.77$ & 2.15 & 4.13 & 39.26 & $0.71-0.32$ \\
F6 & $0.34-0.63$ & 1.66 & 3.20 & 42.46 & $0.91-0.41$ \\
F7 & $0.31-0.62$ & 1.38 & 3.07 & 45.53 & $0.81-0.49$ \\
F8 & $0.48-0.77$ & 1.15 & 2.65 & 48.18 & $0.76-0.31$ \\
\hline
\end{tabular}

also considered the scale appropriate in terms of sentence length. Based on these evaluations, the instrument was deemed ready for implementation.

\section{Definitive Instrument (Factor Analyses)}

To determine the construct validity of the scale, the values for the KMO (.95) and Bartlett's test of sphericity $\left(X^{2}: 69484.88 ; p<.00\right)$ were considered significant, and it was accepted that the survey data were appropriate for the factor analysis. In order to decide the number of factors in the scale, exploratory factor analysis (EFA) was applied to the 64 items, and the eigenvalues, percentage of total variance explained, and factor loadings were examined. Based on the EFA, eight factors were obtained. The total contribution of the eight factors to the variance was found to be $50.39 \%$. The factor loadings of the items with eigenvalues higher than 1.15 varied between .31 and .91. The eigenvalues, percentage of total variance explained, and factor loadings of the factors in the scale are presented in Table 1.

The resulting eight factors were evaluated in terms of content integrity, following which the following subscales were established: management, teaching, teaching staff, institutional commitment, emotions, inter-student relationships, physical environment, and motivation. When the subscales were named, logical and semantic relationships between the items were taken into account and the entire conceptual framework was included.

Based on the responses given by the preclinical medical students during the development stage of the PLCS, the expected min-max scores and observed mean scores of the scale and subscales were obtained (Table 2).

The ratio of the observed mean score to the expected max score obtained from the scale ranged from $54 \%$ to $77 \%$. Although the observed mean score close to the expected maximum score of the scale indicates that preclinical learning climate was perceived positively, the observed mean score close to the expected minimum score of the scale indicates the problematic areas of the learning climate.

Based on the EFA, 12 items were removed from the scale since their factor loadings were under .30, which was considered the threshold value. Construct validity of definitive instrument was established, following which the subscales (and the items under each subscale) were renumbered. The resulting instrument, the PLCS, includes 52 items, four of which are reversely scored (Items Nos. 45 , 46,47 , and 54).

Upon completion of the discriminant validity analysis, it was determined that the instrument

\begin{tabular}{|c|c|c|c|c|}
\hline \multicolumn{5}{|c|}{$\begin{array}{l}\text { Table } 2 \\
\text { The Number of the Items in the Subscales and the Subscale Scores }\end{array}$} \\
\hline Factors & Subscales & The Number of the Item & Min-Max Score & Observed Mean Score (SD) \\
\hline $\mathrm{F} 1$ & Management & 7 & $7-35$ & $18.95(5.21)$ \\
\hline $\mathrm{F} 2$ & Teaching & 11 & $11-55$ & $32.84(7.00)$ \\
\hline F3 & Teaching Staff & 9 & $9-45$ & $29.57(5.46)$ \\
\hline $\mathrm{F} 4$ & Institutional Commitment & 7 & $7-35$ & $21.60(5.46)$ \\
\hline F5 & Emotions & 5 & $5-25$ & $14.03(4.43)$ \\
\hline F6 & Inter-Student Relationships & 5 & $5-25$ & $15.78(3.36)$ \\
\hline F7 & Physical Environment & 5 & $5-25$ & $16.11(3.48)$ \\
\hline F8 & Motivation & 3 & $3-15$ & $11.49(2.32)$ \\
\hline \multicolumn{2}{|c|}{ Total PLCS score } & 52 & $52-260$ & $160.37(26.07)$ \\
\hline
\end{tabular}




\begin{tabular}{|c|c|c|c|c|c|c|}
\hline \multicolumn{7}{|c|}{$\begin{array}{l}\text { Table } 3 \\
\text { Distribution of the PLCS Scores in terms of Independent Variables }\end{array}$} \\
\hline Independent Variables & & $N$ & Mean & $S D$ & $t / F$ & $p$ \\
\hline \multirow{2}{*}{ Faculty educational program type } & Problem-based learning & 1126 & 165.48 & 25.45 & \multirow{2}{*}{$8.04^{*}$} & \multirow{2}{*}{0.00} \\
\hline & System-based integration & 2414 & 157.98 & 26.01 & & \\
\hline \multirow{3}{*}{ Year at school } & 1 & 1357 & 167.00 & 24.78 & \multirow{3}{*}{$83.41^{* *}$} & \multirow{3}{*}{0.00} \\
\hline & 2 & 1140 & 158.43 & 25.63 & & \\
\hline & 3 & 1043 & 153.85 & 26.21 & & \\
\hline \multirow{2}{*}{ Repeating the class } & Yes & 200 & 155.57 & 28.18 & \multirow{2}{*}{$2.69^{*}$} & \multirow{2}{*}{0.0} \\
\hline & No & 3340 & 160.66 & 25.91 & & \\
\hline \multirow{2}{*}{ Choosing the faculty on his/her own will } & Yes & 3013 & 161.96 & 25.45 & \multirow{2}{*}{$8.29^{*}$} & \multirow{2}{*}{0.00} \\
\hline & No & 527 & 151.26 & 27.66 & & \\
\hline \multirow{3}{*}{ Academic grade point average } & $\leq 59$ & 237 & 155.63 & 26.66 & \multirow{3}{*}{$11.65^{\star *}$} & \multirow{3}{*}{0.00} \\
\hline & $60-84$ & 3050 & 160.21 & 25.98 & & \\
\hline & $85-100$ & 253 & 166.76 & 25.51 & & \\
\hline \multirow{3}{*}{ Perception of success } & Not successful & 591 & 149.43 & 27.36 & \multirow{3}{*}{$109.75^{\star *}$} & \multirow{3}{*}{0.00} \\
\hline & $\begin{array}{l}\text { Moderately } \\
\text { successful }\end{array}$ & 1849 & 159.21 & 24.38 & & \\
\hline & Successful & 1100 & 168.19 & 25.67 & & \\
\hline
\end{tabular}

*t-test

** One-way ANOVA

could discriminate the students according to the following independent variables: curriculum, year at school, repeating the class, choosing the faculty on his/her own will, academic grade point average, and perception of success (Table 3 ).

\section{Preclinical Learning Climate Scale}

For the internal consistency analysis, Cronbach's alpha coefficient was .94, while the Cronbach's alpha coefficients of the subscales ranged from .72 to .77. The item-total correlation coefficients of the subscales were found to be between .44 and .76. All the items significantly discriminated between lowand high-performing students $(t=99.57 ; p=.01)$. Based on the results of the analysis, the PCLS was found to be a reliable scale.

In Table 4, the items of the PLCS are presented according to the factor loadings of the subscales determined through the EFA. In addition, Cronbach's alpha $(\alpha)$ and the item-total correlation coefficient (r) of each subscale are given.

As a result of the analysis, the 52-item PLCS, comprising eight subscales, was developed and the validity and reliability of the scale were established. The possible minimum and maximum scores obtained from the scale were 52 and 260 , respectively.

\section{Discussion}

In this study, the Preclinical Learning Climate Scale (PLCS) was developed to determine medical students' perceptions of the preclinical learning climate. The methodology, recommended by McKenzie, Wood, Kotecki, Clark, and Brey (1999), Delamere, Wankel, and Hinch (2001), Worthington and Whittaker (2006), and Ringsted, Hodges, and Scherpbier (2011) included the following activities: generate an item pool, receive expert opinions, perform a pretest to purify the instrument, and conduct factor and reliability analyses.

In general, content validity plays an important role in the assessment of the validity criteria when developing any type of scale. To achieve this purpose, the present study conducted a literature review, observations and discussions with experts, qualitative and quantitative content evaluations, structured/unstructured observations, focus groups, etc. (Soemantri et al., 2010). In addition, content validity evidence was obtained through the literature-based item pool, the Delphi panel technique, and outside expert opinions.

Factor analysis is a fundamental step in demonstrating the construct validity when developing any scale (DeVellis, 2003; Johnson \& Wichern, 2002; Tabachnick \& Fidell, 2001). In the present study, the construct validity of the scale was demonstrated through exploratory factor analysis. In addition, the total contribution of the eight factors to the variance was $50.39 \%$. According to Scherer, Wiebe, Luther, and Adams (1988), the percentage of total variance between $40 \%$ and $60 \%$ is appropriate in multifactorial designs. Thus, the contribution of the aforementioned eight factors to the total variance was appropriate in this study. 


\begin{tabular}{|c|c|c|}
\hline \multicolumn{3}{|c|}{$\begin{array}{l}\text { Table } 4 \\
\text { The Subscales of the PLCS Determined according to Factor Loadings }\end{array}$} \\
\hline Subscale & $\begin{array}{l}\text { Item-total } \\
\text { correlation }\end{array}$ & Items \\
\hline \multirow{7}{*}{$\begin{array}{l}\text { Management } \\
\alpha=0.73 \\
r=0.73\end{array}$} & 0.56 & 62. The consulting services provided for the students in the school are sufficient. \\
\hline & 0.57 & 60. At the school, the students can voice their concerns in the decision-making process. \\
\hline & 0.55 & 61. The school administration takes into account the feedback from the students. \\
\hline & 0.51 & 59. The school also provides opportunities for students to become involved in non-medical pursuits. \\
\hline & 0.44 & 43. The student affairs unit at the school displays a supportive attitude toward students. \\
\hline & 0.53 & 32. The school administration is closely concerned with the students' problems. \\
\hline & 0.58 & 63. The quality of the education is of importance to the school administration. \\
\hline \multirow{11}{*}{$\begin{array}{l}\text { Teaching } \\
\alpha=0.72 \\
r=0.75\end{array}$} & 0.49 & 4. The teaching is conducted in a manner that provides the skills necessary to serve in my profession. \\
\hline & 0.53 & $\begin{array}{l}\text { 3. The teaching is conducted in a manner that provides the knowledge necessary to serve in my } \\
\text { profession. }\end{array}$ \\
\hline & 0.51 & 2. The teaching encourages me to become an active learner. \\
\hline & 0.57 & 12. The teaching ensures the development of my critical thinking and evaluation skills. \\
\hline & 0.48 & $\begin{array}{l}\text { 5. The teaching is conducted in a manner that provides the attitudes and behaviors necessary to } \\
\text { serve in my profession. }\end{array}$ \\
\hline & 0.45 & 1. The students clearly know what they are supposed to learn. \\
\hline & 0.50 & 11. The recommended learning resources are helpful for the students. \\
\hline & 0.63 & 13. I feel that I am receiving quality training. \\
\hline & 0.51 & 23. The contents of the exams focus on topics that I will use in my profession. \\
\hline & 0.52 & 22. The students know what is expected of them in the exams. \\
\hline & 0.40 & $\begin{array}{l}\text { 10. The students are informed about the learning resources (i.e., books, presentations, electronic } \\
\text { resources, etc.) that we need to use in advance. }\end{array}$ \\
\hline \multirow{9}{*}{$\begin{array}{l}\text { Teaching staff } \\
\alpha=0.73 \\
r=0.73\end{array}$} & 0.46 & 34. The teachers are prepared for their classes. \\
\hline & 0.39 & 35. The teachers are knowledgeable about their area of specialization. \\
\hline & 0.49 & 40. The teachers behave respectfully toward the students. \\
\hline & 0.57 & 38. The teachers feel responsible for encouraging students to learn. \\
\hline & 0.54 & 36. The way that the teachers provide training is good. \\
\hline & 0.51 & 41. The teachers believe that students can be successful. \\
\hline & 0.53 & 39. The teachers are open to students' different opinions and ideas. \\
\hline & 0.56 & 33. The teachers are willing to take part in the students' training. \\
\hline & 0.52 & 42. The students have easy access to teachers when needed. \\
\hline \multirow{7}{*}{$\begin{array}{l}\text { Institutional } \\
\text { commitment } \\
\alpha=0.73 \\
r=0.76\end{array}$} & 0.62 & 58. I am proud of my school. \\
\hline & 0.61 & 53. I feel that I belong to my school. \\
\hline & 0.66 & 50. I am pleased to be a student in this school. \\
\hline & 0.64 & 52. I feel valuable in the school. \\
\hline & 0.62 & 51. I feel that I am generally trusted in the school. \\
\hline & 0.41 & 54. This school has disappointed me. \\
\hline & 0.52 & 64. I feel safe on campus and in the hospital. \\
\hline \multirow{5}{*}{$\begin{array}{l}\text { Emotions } \\
\alpha=0.75 \\
r=0.50\end{array}$} & 0.35 & 45. During this academic year, I feel depressed. \\
\hline & 0.39 & 46. During this academic year, I feel angry. \\
\hline & 0.33 & 47. During this academic year, I feel anxious. \\
\hline & 0.60 & 49. During this academic year, I generally feel good. \\
\hline & 0.48 & 48. During this academic year, I have been able to allocate time for myself. \\
\hline \multirow{5}{*}{$\begin{array}{l}\text { Inter-student } \\
\text { relationships } \\
\alpha=0.76 \\
r=0.57\end{array}$} & 0.37 & 25. The students in the classroom know one another. \\
\hline & 0.52 & 26. There is a positive/relaxing atmosphere in our classroom. \\
\hline & 0.41 & 27. In our school, the students behave respectfully toward one another. \\
\hline & 0.37 & 30. There is a supportive relationship between the junior and senior students in the school. \\
\hline & 0.39 & 28. There is an environment for students to get together in the school. \\
\hline \multirow{5}{*}{$\begin{array}{l}\text { Physical } \\
\text { environment } \\
\alpha=0.75 \\
r=0.57\end{array}$} & 0.43 & 18. The school provides convenient and comfortable study areas for the students. \\
\hline & 0.36 & 17. The locations (i.e., classrooms, labs, learning resource center, etc.) that I make use of are clean. \\
\hline & 0.43 & $\begin{array}{l}\text { 15. The learning resources (i.e., printed or electronic documents, manikins, models, etc.) are } \\
\text { provided by the school so that the students can easily access them. }\end{array}$ \\
\hline & 0.38 & $\begin{array}{l}\text { 19. The locations used for purposes other than education (i.e., canteen, cafeteria, toilets, etc.) meet } \\
\text { the needs of the students. }\end{array}$ \\
\hline & 0.41 & $\begin{array}{l}\text { 44. The school staff (i.e., laboratory workers, cleaners, canteen staff, etc.) display supportive attitudes } \\
\text { toward the students. }\end{array}$ \\
\hline \multirow{3}{*}{$\begin{array}{l}\text { Motivation } \\
\alpha=0.77 \\
r=0.44\end{array}$} & 0.31 & 56. I am willing to learn about topics related to my profession. \\
\hline & 0.31 & 55. I want to become a physician. \\
\hline & 0.57 & 57. The teaching ensures the development of my professional self-confidence. \\
\hline
\end{tabular}


Hair et al. (1988) recommended a certain sample size for factor loading values. The sample size in the present study is suitable since the cut-off value of .30 was used to determine factor loads. When the items included in the sub-scales are evaluated from this perspective, they are considered to have been sufficiently loaded.

The eight-subscale model included the following factors:

Management: This factor examines the learning climate from the perspective of education management, which includes administrative features such as allowing students to participate in the decision-making process, dealing with students' problems, and providing support and counseling.

Teaching: This factor focuses on the teaching strategies and the impact of measurement-assessment activities on students and the learning climate.

Teaching staff: This factor investigates educators' versatile and challenging roles (other than the transfer of information) that affect the learning climate.

Institutional commitment: This factor includes items related to students' sense of belonging to their institution.

Emotions: This factor assesses students' affective perceptions of the learning environment.

Inter-student relationships: This factor assesses the effects of trust, value, and communication on the learning climate, especially in terms of intra-class and intra-faculty interactions.

Physical environment: This factor focuses on the location of educational activities, learning resources, and logistical support, all of which have an effect on the learning climate.

Motivation: This factor examines the impact of the learning environment on motivation, in addition to the students' intrinsic motivation.

While the PLCS had similarities with some of the previously developed learning climate scales, it differed in terms of the names of the subscales. The following are the commonalities and differences between the PLCS and other learning climate scales:

1) The teaching subscale is also included in the DREEM (Roff et al., 1997), the Practice-based Educational Environment Measure (PEEM) (Mulrooney, 2005), and the Postgraduate Hospital Educational Environment Measure (PHEEM) (Roff, 2005).

2) The teaching staff subscale is also included in several other scales. However, it is referred to as teachers in the DREEM (Roff et al., 1997) and the CLCS (Wangsaturak \& McAleer, 2008), as coaching and assessment in the Dutch Residency Educational Climate Test (D-RECT) (Boor, van Der Vleuten, Teunissen, Scherpbier, \& Scheele, 2011), as trainer and training in the Surgical Theatre Educational Environment Measure (STEEM) (Cassar, 2004), and as teaching and teachers in The Anaesthetic Theatre Educational Environment Measure (ATEEM) (Holt \& Roff, 2004).

3) The inter-student relationship subscale is referred to as student-interaction in the Medical School Learning Environment Questionnaire (LEQ) (Rothman \& Ayoade 1970).

4) The management subscale is referred to as organization and flexibility in the MSLES (Marshall, 1978), and as student involvement (in curriculum etc.) and administratively flexible in the Medical School Environment Questionnaire (MSEQ) (Wakeford, 1981).

5) The emotions subscale is referred to as academic enthusiasm in the LEQ (Rothman \& Ayoade, 1970), as emotional climate in the MSLES (Marshall, 1978), and as enjoyable in the MSEQ (Wakeford, 1981).

6) The physical environment subscale is referred to as physical environment and educational resources in the CLCS (Wangsaturak \& McAleer, 2008).

7) The motivation subscale is referred to as intellectual maturity in the LEQ (Rothman \& Ayoade, 1970) and as motivation in the CLCS (Wangsaturak \& McAleer, 2008).

8) The institutional commitment subscale included in the PLCS is not included in the other scales nor is it referred to by any other name.

When the PLCS is compared with other learning climate scales, two features distinguish it from the other scales. First, some items included in the subscales of the PLCS show a holistic structure. Second, the institutional commitment subscale is included as a new conceptual dimension in the learning climate.

According to the discriminant validity analysis, the scores from the variables, such as the faculty education program type, year at school, repeating the class, choosing the faculty on his/ her own will, academic grade point average, and perception of success, differed significantly. This finding demonstrates that the differences between students according to these variables refer to its discrimination strength. This also supports the construct validity of the scale. 
In the development of any scale, inter-rater reliability, item discrimination test, internal consistency, Cronbach's alpha, test-retest measures, and generalizability analysis are used to estimate overall reliability (Dornan et al., 2011). In the present study, Cronbach's alpha, item-total correlation, and the item discrimination test were conducted. It has been shown that a Cronbach's alpha coefficient of greater than .70 indicates high reliability (Munro, 2005). Since the Cronbach's alpha coefficient in the PLCS was above .70, this scale was deemed highly reliable. It has been recommended that the item-total correlation coefficient, which indicates the contribution of each item to the entire scale, should be at least .30 (Streiner \& Norman, 2008). In the present study, the item-total correlation coefficient for all of the subscales was above .44 , which suggests that the items included in each subscale were consistent with one another. Finally, according to the item discrimination test results, all of the items were significantly discriminated between the low- and high-performing students. All these findings indicate that the PLCS is highly reliable.

In this study, validity evidence was assessed in accordance with the sources developed by The American Psychological Association (APA), the American Education Research Association (AERA), and the National Council on Measurement in Education (NCMA) (1999). The validity evidence obtained according to these criteria indicates that the PLCS is a valid and reliable instrument.

The aforementioned findings concerning the validity and reliability of the scale indicate that the PLCS provides valid and reliable scores, and it can be used to assess medical students' perceptions of the learning climate in the preclinical phase. The following are the strengths of the scale:

1) It covers all observed factors that affect learning during the preclinical period;

2) It includes items regarding students' participation in the management process;

3) It includes the teaching subscale with items such as identification of students' needs, educational objectives and strategies, and sources related to testing and learning;

4) It includes the institutional commitment subscale, which is unique to the scale;

5) The scale was administered to a large sample group, which increased the evidentiary value of the validity and reliability analyses;

6) The scale can measure the learning climate in medical schools with different education programs.
Finally, in the literature (Cohen, 2006; Dornan et al., 2011), the importance and effects of the learning climate have been identified. However, since the learning climate covers all the variables that affect learning, researchers have focused on the different aspects of the learning climate, which has resulted in a number of scales with different dimensions. Therefore, the PLCS was structured to include all of the observed factors that affect learning in the preclinical stage in medical schools. It excludes no dimension regarding the learning climate, but includes the institutional commitment subscale, which is unique to the scale.

Finally, this study includes several limitations. First, the findings are specific to the preclinical stage in medical schools and the scale cannot be used in other stages of medical education. Second, since the number of items in the scale is considerable, the time required to administer the scale can vary widely. Third, generalizability analysis, which analyzes the reliability of the evidence under specific conditions, was not conducted in this study. Therefore, future studies should further refine and evaluate the generalizability of this scale.

\section{Conclusions}

In this study, the primary reason why the new scale was developed, rather than using an established scale (e.g., the DREEM), is that previous scales cannot fully examine climatic factors that affect the educational environments in medical schools. Thus, the 52-item PLCS was developed as a measurement tool to assess the preclinical learning climate in medical schools. The scale included eight subscales: management, teaching, teaching staff, institutional commitment, emotions, inter-student relationships, physical environment, and motivation. The results suggest initial support for the new instrument as a measure of preclinical medical students' perceptions of the learning climate. However, although the authors of this study recommend that the PLCS be used as a valid and reliable tool for the evaluation of the preclinical period in medical schools, they also suggest that future studies that plan to use the PLCS should perform confirmatory factor analysis and generalizability analysis in the case of applying the scale in different cultures.

Acknowledgments: The authors would particularly like to thank all the medical students who participated in this study. 


\section{References}

American Educational Research Association, American Psychological Association, and National Council on Measurement in Education. (1999). Standards for educational and psychological testing. Washington, DC: American Educational Research Association.

Boor, K., van Der Vleuten, C., Teunissen, P., Scherpbier, A., \& Scheele, F. (2011). Development and analysis of D-RECT, an instrument measuring residents' learning climate. Medical Teacher, 33, 820-827.

Cassar, K. (2004). Development of an instrument to measure the surgical operating theatre learning environment as perceived by basic surgical trainees. Medical Teacher, 26, 260-264.

Cate, O. T. (2007). Medical education in the Netherlands. Medical Teacher, 29, 752-757.

Cohen J. (2006). Social, emotional, ethical, and academic education: Creating a climate for learning, participation in democracy, and well-being. Harvard Educational Review 76(2), 201-237.

Dahlin, M. E., \& Runeson, B. (2007). Burnout and psychiatric morbidity among medical students entering clinical training: A three year prospective questionnaire and interview-based study. BMC Medical Education, 7, 6.

Delamere, T. A., Wankel, L. M., \& Hinch, T. D. (2001) Development of a scale to measure resident attitudes toward the social impacts of community festivals, Part I: Item generation and purification of the measure. Event Management, 7, 11-24.

Demiral-Yllmaz, N. (2010). The examination of medicine students' learning climate perceptions regarding the academical self efficacy, attitude towards medicine occupation and academical success (Doctoral dissertations, Ege University, Institute of Social Sciences, Department of Educational Sciences, İzmir, Turkey). Retrieved from https://tez.yok.gov.tr/UlusalTezMerkezi/

Demirören, M., Palaoglu, Ö., Kemahli, S., Özyurda, F., \& Ayhan, H. I. (2008). Perceptions of students in different phases of medical education of educational environment: Ankara University Faculty of Medicine. Med Educ Online [serial online], 13,8 .

DeVellis, F. R. (2003). Scale development theory and applications (2nd ed.). California, CA: Sage.

Dornan, T., Mann, K., Scherpbier, A., Spencer, J., \& Norman, G. (2011). Medical education theory and practice. Edinburgh, UK: Churchill Livingstone.

Genn, J. M. (2001). AMEE Medical Education Guide No. 23 (Part 1): Curriculum, environment, climate, quality and change in medical education a unifying perspective. Med Teacher, 23(5), 445-454.

Hair, J. F., Tatham, R. L., Anderson, R. E., \& Black, W. (1998). Multivariate data analysis (5th ed.). London, UK: Prentice-Hall.

Harden, R. M., \& Davis, M. H. (1995). AMEE Medical Education Guide No. 5: The core curriculum with options or special study modules. Medical Teacher, 17(2), 125-148.

Holt, M. C., \& Roff, S. (2004). Development and validation of the anaesthetic theatre educational environment measure (ATEEM). Medical Teacher, 26, 553-558.

Johnson, R. A., \& Wichern, D. W. (2002). Applied multivariate statistical analysis. New Jersey, NJ: Prentice Hall.

Kennedy, C., Lilley, P., Kiss, L., Littvays, L., \& Harden, R. (2013). MEDINE2 Work Package 5: Curriculum trends in medical education in Europe in the 21st century. Retrieved from http://medine2.com/Public/docs/MEDINE2-WP5.pdf
Lawshe, C. H. A. (1975). A quantitative approach to content validity. Personnel Psychology, 28, 563-575.

Marshall, R. E. (1978). Measuring the medical school learning environment. Journal of Medical Education, 53, 98-104.

McClean, M. (2004). Sometimes we do get it right! Early clinical contact is a rewarding experience. Education for Health, 17(1), 42-52.

McKenzie, J. F., Wood, M. L., Kotecki, J. E., Clark, J. K., \& Brey, R. A. (1999). Establishing content validity: Using qualitative and quantitative steps. American Journal of Health Behavior, 23(4), 311-318.

Mulrooney, A. (2005). Development of an instrument to measure the practice vocational training environment in Ireland. Medical Teacher, 27, 338-342.

Munro, B. H. (2005). Statistical methods for health care research (5th ed.). Philadelphia, PA: Lippincott Williams \& Wilkins.

Nunnaly, J. (1978). Psychometric theory. New York, NY: McGraw-Hill.

Polali, L., \& Price, J. (2000). Developments: Validation and use of an instrument to measure the learning environment as perceived by medical students. Teaching and Learning in Medicine, 12(4), 201-207.

Riley, S. C. (2009). AMEE Medical Education Guide No. 46: Student Selected Components (SSCs). Medical Teacher, $31,885-894$

Ringsted, C., Hodges, B., \& Scherpbier, A. (2011). AMEE Medical Education Guide No 56: The research compass': An introduction to research in medical education. Medical Teacher, 33, 695-709.

Roff, S. (2005). The Dundee Ready Educational Environment Measure (DREEM)-a generic instrument for measuring students' perceptions of undergraduate health professions curricula. Medical Teacher, 27(4), 322-325.

Roff, S., \& McAleer, S. (2001). What is educational climate? Medical Teacher, 23(4), 333-334.

Roff, S., McAleer, S., Harden, R. M., \& Al-Qahtani, M. A. (1996). Development of a validated Medical Education Environment Measure (MEEM). Proceedings of the Meeting of the Scottish Educational Research Association.

Roff, S., McAleer, S., Harden, R. M., Al-Qahtani, M., Ahmed, A. U., Deza, H. ... Primparyon, P. (1997). Development and validation of the Dundee Ready Education Environment Measure (DREEM). Medical Teacher, 19(4), 295-299.

Rothman, A. I., \& Ayoade, F. (1970). The development of a learning environment: A questionnaire for use in curriculum evaluation. Journal of Medical Education, 45, 754-759.

Sandars, J., Patel, R., Steele, H., \& Mcareavey, M. (2014). AMEE Medical Education Guide No 92: Developmental student support in undergraduate medical education. Medical Teacher, 36, 1015-1026.

Scherer, R. F., Wiebe, F. A., Luther, D. C., \& Adams, J. S. (1988). Dimensionality of coping: Factor stability using the ways of coping questionnaire. Psychological Reports, 62, 763-770.

Schönrock-Adema, J., Bouwkamp-Timmer, T., van Hell, E. A., \& Cohen-Schotanus, J. (2012). Key elements in assessing the educational environment: where is the theory? Advances in Health Sciences Education, 17, 727-742.

Sharma, S. (1996). Applied multivariate techniques. New York, NY: John Wiley and Sons. 
Soemantri, D., Herrera, C., \& Riquelme, A. (2010). Measuring the educational environment in health professions studies: A systematic review. Medical Teacher BEME Rapid Review, 32, 947-952.

Strand, P., Sjöborg, K., Stalmeijer, R., Wichmann-Hansen, G., Jakobsson, U., \& Edgren, G. (2013). Development and psychometric evaluation of the Undergraduate Clinical Education Environment Measure (UCEEM). Medical Teacher, 35, 1014-1026.

Streiner, L. D., \& Norman, G. R. (2008). Health measurement scales. A practical guide to their development and use (4th ed.) New York, NY: Oxford University Press.

Tabachnick, B. G., \& Fidell, L. S. (2001). Using multivariate statistics. Boston, MA: Allyn and Bacon A Pearson Education Company.
Veneziano, L., \& Hooper, J. (1997). A method for quantifying content validity of health-related questionnaires. American Journal of Health Behavior, 21(1), 67-70.

Wakefort, R. E. (1981). Students' perception of the medical school learning environment: A pilot study into some differences and similarities between clinical schools in the UK. Assessment and Evaluation in Higher Education, 6, 206-217.

Wangsaturak, D., \& McAleer, S. (2008). Development of the clinical learning climate measure for undergraduate medical education. South East Asian Journal of Medical Education, 2(2), 41-51.

WFME Standards. (2003). Basic Medical Education WFME Global Standards for Quality Improvement. University of Copenhagen Denmark.

Worthington, R., \& Whittaker, T. (2006). Scale development research: A content analysis and recommendations for best practices. Counseling Psychologist, 34, 806-838. 
